\title{
Questionnaire survey on medical futility and termination of resuscitation in cardiac arrest patients among emergency physicians in Hong Kong
}

\author{
CW So, CT Lui *, KL Tsui, KL Chan, Alex KK Law, YK Wong, T Li, CL Wong, SC Leung
}

\section{A B S T R A C T}

Introduction: The perceptions of medical futility and decisions about termination of resuscitation (TOR) for out-of-hospital cardiac arrest (OHCA) are highly heterogeneous and dependent on the practice of the attending emergency physicians. The objective of this study was to report and investigate the knowledge, attitudes, and practices regarding medical futility and TOR during management of $\mathrm{OHCA}$ in Hong Kong.

Methods: A cross-sectional survey was conducted among emergency medicine physicians in Hong Kong. The questionnaire assessed participants' background, knowledge, attitudes, and behaviours concerning medical futility and TOR in management of OHCA. Composite scores were calculated to reflect knowledge, attitudes, and practices of OHCA treatment. Subgroup analysis and multiple regression analysis were used to explore the relationship between participants' background, knowledge, attitudes, and behaviours.

Results: The response rate to this survey was $57 \%(140 / 247)$. Independent predictors of less aggressive resuscitation in OHCA patients included status as a Fellow of the Hong Kong College of Emergency Medicine $(\beta=-0.314, \quad \mathrm{P}=0.028)$ and being an Advanced Cardiac Life Support instructor $(\beta=-0.217, P=0.032)$. There was no difference in aggressiveness of resuscitation in terms of years of clinical experience $(\beta=0.015, P=0.921)$, knowledge of TOR $(\beta=0.057, P=0.509)$, or attitudes about TOR $(\beta=$ $-0.103, P=0.214)$. The correlation between knowledge
TOR was not demonstrated to have associations with knowledge or attitude. Status as a Fellow of the Hong Kong College of Emergency Medicine or Advanced Cardiac Life Support instructor were the only two parameters identified that had significant relationships with earlier TOR in medically futile patients with OHCA.

\section{Hong Kong Med J 2019;25:183-91} https://doi.org/10.12809/hkmj187755

${ }^{1} \mathrm{CW}$ So, $\mathrm{MB}, \mathrm{ChB}$

${ }^{1}$ CT Lui *, FHKCEM, FHKAM (Emergency Medicine)

${ }^{2}$ KL Tsui, FHKCEM, FHKAM (Emergency Medicine)

${ }^{3} \mathrm{KL}$ Chan, FHKCEM, FHKAM (Emergency Medicine)

${ }^{4}$ AKK LaW, FHKCEM, FHKAM (Emergency Medicine)

${ }^{5}$ YK Wong, FHKCEM, FHKAM (Emergency Medicine)

${ }^{6} \mathrm{~T} \mathrm{Li}, \mathrm{MB}, \mathrm{ChB}$

${ }^{7}$ CL Wong, FHKCEM, FHKAM (Emergency Medicine)

${ }^{8}$ SC Leung, FHKCEM, FHKAM (Emergency Medicine)

1 Department of Accident and Emergency, Tuen Mun Hospital, Tuen Mun, Hong Kong

2 Department of Accident and Emergency, Pok Oi Hospital, Yuen Long, Hong Kong

${ }^{3}$ Department of Accident and Emergency, Queen Elizabeth Hospital, Jordan, Hong Kong

Department of Accident and Emergency, Prince of Wales Hospital, Shatin, Hong Kong

5 Department of Accident and Emergency, Kwong Wah Hospital, Yaumatei, Hong Kong

Department of Accident and Emergency, Tseung Kwan O Hospital, Tseung Kwan O, Hong Kong

Department of Accident and Emergency, Princess Margaret Hospital, Laichikok, Hong Kong

${ }^{8}$ Accident and Emergency Department, Queen Mary Hospital, Pokfulam, Hong Kong

Corresponding author: luict@ha.org.hk

New knowledge added by this study

- Fellowship in emergency medicine and instructorship in resuscitation courses were two independent predictors of less aggressive resuscitation in medically futile patients with out-of-hospital cardiac arrest. Knowledge level and attitude do not predict behaviour and practice well.

Implications for clinical practice or policy

- The survey reports knowledge, attitudes, and practice of termination of resuscitation in medically futile situations of out-of-hospital cardiac arrest among emergency physicians in Hong Kong. Early prognostication to identify medically futile patients for diversion of care to bereavement and family support should be part of resuscitation training. 


\section{有關香港急症科醫生對心搏停止病人的無效醫療 和停止搶救概念的問卷調查

\author{
蘇頌威、雷俊達、徐國樑、陳建凌、羅國強、黃英傑、李田、 \\ 黃祥麟、梁兆琮
}

引言：急症科醫生對於心搏停止的病人都有不同的處理方法。本問卷 調查旨在對無效醫療和終止搶救概念上的知識、態度和做法作出研 究。

方法: 這項對香港急症科醫生的橫斷式問卷調查, 內容包括參與者的 背景資料以及對無效醫療和終止搶救概念上的知識、態度和做法。每 一部分都會計算出相應的分數, 然後以次群體分析和多元迴歸分析計 算出參數間的相互關係。

結果 : 本次問卷調查的回覆率為 $57 \%$ 。我們發現引致較不進取搶救的 獨立變數為香港急症科醫學院院士 $(\beta=-0.314, \mathrm{P}=0.028)$ 和高階心 肺急救術（ACLS）導師（ $\beta=-0.217, P=0.032 ）$, 而年資（ $\beta=0.015$, $\mathrm{P}=0.921)$ 和對終止搶救的知識 $(\beta=0.057, \mathrm{P}=0.509)$ 和態度 $(\beta=$ $-0.103, \mathrm{P}=0.214)$ 並未發現足以影響對搶救的進取程度。知識和態度 間的相關性也較低（Spearman's coefficient $=0.02, \mathrm{P}=0.795$ ）。

結論：對終止搶救的知識和態度與做法無顯著相關。持有香港急症科 醫學院院士和ACLS 導師資格是降低對心搏停止病人作出搶救的進取 程度的唯二因素。

\section{Introduction}

Out-of-hospital cardiac arrest (OHCA) is commonly encountered in emergency departments (EDs), with an incidence rate of 72 per 100000 person-years in Hong Kong. ${ }^{1}$ The 30 -day survival or survival-todischarge rate of OHCA patients has been reported as $2.3 \%$ in Hong Kong, ${ }^{1}$ with only $1.5 \%$ of all OHCA patients having good neurological outcomes. ${ }^{1}$ Within the group of patients in whom resuscitation failed, a large proportion presented with unwitnessed prehospital asystolic cardiac arrest. Resuscitation in this group of patients is considered medically futile, and termination of resuscitation (TOR) is supported by validated clinical prediction rules. ${ }^{2-6}$ Therefore, it is reasonable to perform early prognostication and identify the group of patients in whom resuscitation is medically futile for familial bereavement support.

The perception of medical futility and the practice of TOR for patients with OHCA are highly heterogeneous among emergency physicians in Hong Kong. In addition to patient factors and the circumstances of the cardiac arrest, decisions about TOR in emergency rooms are also affected by the knowledge and attitudes of the resuscitation team about medical futility, the social and cultural beliefs of relatives and society, and legal considerations. There have been few reports in the literature about knowledge, attitudes, and practices on this issue. The objective of this study was to report the knowledge, attitudes, and practices regarding medical futility and TOR during management of OHCA in Hong Kong and investigate the relationships of this knowledge and these attitudes to practice.

\section{Methods}

\section{Study setting and participants}

A survey on knowledge, attitudes, and behaviours (KAB) concerning TOR in OHCA was conducted on emergency medicine (EM) physicians currently working in nine EDs in Hong Kong from January to June 2018. The survey was conducted in the form of printed questionnaires written in English. Target participants included trainees or Fellows of the Hong Kong College of Emergency Medicine (Fellows). Doctors registered under other specialties who were working in EDs were excluded.

\section{Questionnaire tool}

A literature search revealed no validated questionnaires that assess the $\mathrm{KAB}$ of physicians on TOR for OHCA. Therefore, relevant questions on $\mathrm{KAB}$ were designed based on multiple previous studies concerning similar topics. ${ }^{7-10}$ Evaluation of the questionnaire's internal consistency was performed using Cronbach's alpha.

This questionnaire consisted of five domains of questions in the formats of binary (Yes/No) questions, 5-point Likert scale questions, and openended questions (Table 1). To avoid learning bias, the sequence of questions was rearranged in the final questionnaire.

The five domains included: (1) demographic data of the participants; (2) knowledge on TOR; (3) attitudes towards TOR; (4) behaviours in TOR; and (5) miscellaneous.

The first domain contained questions that obtained the participants' baseline characteristics, including their fellowship status, clinical experience, and any courses attended on topics related to both resuscitation (such as the Advanced Cardiac Life Support course [ACLS]) and TOR. The results were used to provide the study's demographic data and to analyse the relationship between the participants' background and other variables, including KAB.

The second domain consisted of questions about knowledge of TOR (Table 1). There were eight questions in this domain, which included facts about OHCA in Hong Kong, current validated rules for TOR, and issues related to medical futility. Correct answers were given 1 point for each question. A knowledge composite score ranging from 0 to 8 was calculated for each participant by summation of individual questions' scores. A higher score reflected a higher level of knowledge about OHCA outcomes and the concept of medical futility. 
TABLE I. Domains of questions in the study questionnaire

No. Question
Knowledge on termination of resuscitation (score range: $0-8)^{\star}$
K1 Do you know that there are validated rules for TOR? If the answer is Yes, please state the rule.

K2 Per 100 patients presenting to Accident \& Emergency Departments in Hong Kong with OHCA, how many patients do you think can survive until day 30 , or until hospital discharge?

K3 The following personnel can certify that a patient is dead: in-charge ambulance officer, other ambulance crew members, registered medical practitioner, registered nurse, police officer on scene.

K4 Do-Not-Attempt cardiopulmonary resuscitation order by OHCA patients can be overridden by the attending physician based on one's own clinical judgement.

K5 Medical futility is a subjective decision.

K6 Resuscitation is considered medically NOT futile if return of spontaneous circulation occurs after cardiopulmonary resuscitation.

K7 Cardiac death patients usually can donate the same types and numbers of organs as brain death patients.

K8 Termination of resuscitation is similar to euthanasia.

Attitude on termination of resuscitation (score range: $5-30) \dagger$

A1 Do you think that a rule for termination of resuscitation should be implemented in Accident and Emergency Departments in Hong Kong?

A2 What is your attitude towards euthanasia?

A3 No resuscitation should be performed on arrival at Accident and Emergency Departments for OHCA patients if they are considered medically futile?

A4 In the case of cardiac arrest for $>20$ minutes with no reversible cause, do you think that nonphysicians (eg, ambulance personnel or nurses) can diagnose death at the scene?

A5 In prehospital cardiac arrest, do you think that ambulance personnel could decide not to resuscitate a patient according to protocols (eg, unwitnessed arrest with no bystander CPR/shock, with asystole as the initial rhythm seen by the ambulance crew)?

A6 Ideally, selected family members (eg, calm relatives/parents of children) should be allowed to witness the resuscitation process with a nurse accompanying them.

Behaviour on termination of resuscitation (score range: 0-40)

For the following scenarios, please indicate how long you would resuscitate the patient?

B1 Multiple co-morbidities, aged 85 years, unwitnessed cardiac arrest, asystole as initial rhythm on scene.

B2 Multiple co-morbidities, aged 85 years, witnessed arrest, bystander CPR, asystole as initial rhythm on scene.

B3 Good past health, aged 85 years, unwitnessed cardiac arrest, asystole as initial rhythm on scene.

B4 Good past health, aged 85 years, witnessed cardiac arrest, bystander CPR, asystole as initial rhythm on scene.

B5 Good past health, aged 85 years, witnessed cardiac arrest, bystander CPR + defibrillation, asystole as initial rhythm on scene.

B6 Multiple co-morbidities, aged 40 years, witnessed cardiac arrest, bystander CPR, asystole as initial rhythm on scene.

B7 Good past health, aged 40 years, witnessed cardiac arrest, bystander CPR alone, asystole as initial rhythm on scene.

B8 Good past health, aged 40 years, witnessed cardiac arrest, bystander CPR + defibrillation, asystole as initial rhythm on scene.

B9 Good past health, aged 15 years, unwitnessed cardiac arrest, asystole as initial rhythm on scene.

B10 Good past health, aged 15 years, witnessed cardiac arrest, bystander CPR, asystole as initial rhythm on scene.

Other questions

01 Do you think the presence of relatives would prolong your duration of resuscitation?

Score: 0 to $4(0=$ never; 4 = always $)$

O2 In the past 6 months, how often have you allowed family members to be present during resuscitation?

O3 In the past 6 months, you stopped your resuscitation for medically futile patients because relatives were calm and well accepting.

O4 In the past 6 months, you prolonged your resuscitation for medically futile patients if relatives were not prepared to accept the death of their relatives.

O5 If there is a departmental guideline for TOR, how frequently do you think you will follow the guideline not to initiate resuscitation?

O6 What factor(s) concern you most when you follow/do not follow departmental guidelines for TOR? Open-ended question

Abbreviations: $\mathrm{CPR}=$ cardiopulmonary resuscitation; $\mathrm{OHCA}=$ out-of-hospital cardiac arrest; $\mathrm{TOR}=$ termination of resuscitation

* Composite score to reflect physicians' knowledge on outcomes of out-of-hospital cardiac arrest and concept of medical futility

† Composite score to reflect physicians' open-mindedness towards accepting early termination of futile resuscitation by physicians or trained personnel

and provision of tender loving care to relatives

‡ Composite score indicating how aggressively the physician attempts and continues resuscitation
Positive response (1 point) if answered Yes and stated correct rules. $\%$ and $<5 \%$ gistered medical practitioner.

Yes.

sitive response (1 point) if answered Yes.

(1 point) if answered

Positive response (1 point) if answered No.

Positive response (1 point) if answered No.

Positive response (5 points) if answered Yes.

points

Strongly disagree $=1$ point

Score: 0 to 4 ( $0=$ no resuscitation; $4=$

\section{Remark and score} prolonged resuscitation) 
The third domain included questions assessing participants' attitudes towards TOR (Table 1). There was one binary question with a score of 5 for a positive answer and five Likert-type questions with scores from 1 (strongly disagree) to 5 (strongly agree). An attitude composite score ranging from 5 to 30 was calculated by summation of individual questions' scores. A higher score reflected more open-mindedness to accepting early termination of futile resuscitation and better provision of tender loving care to relatives.

The fourth domain contained ten clinical scenarios concerning OHCA (Table 1). Participants were asked their preferred duration of resuscitation in a range from 0 to 4 , with 0 being no resuscitation and 4 being prolonged resuscitation. A behavioural composite score was calculated by summation of individual questions' scores. A higher score indicated higher aggressiveness towards attempting and continuing resuscitation. The behavioural composite score does not include any specification regarding medicolegal consideration, personal beliefs, or religious context.

The last domain of this questionnaire consisted of six questions about TOR that were not categorised into KAB domains. This domain included questions concerning the effects of the presence of relatives and presence of departmental guidelines on TOR-related decisions.

The questionnaires were distributed to nine EDs in Hong Kong by hand and through internal mailings by the Hospital Authority. One site investigator was designated in each participating ED to distribute and collect the questionnaires from the participants anonymously. Anonymous use of the collected data for research purposes was clearly stated at the start of the questionnaire. All questionnaires were filled and returned on a voluntary basis.

\section{Statistics}

The internal consistency of this questionnaire was assessed with Cronbach's alpha. Descriptive analysis is reported for the questionnaire response of each domain. Median and interquartile range (IQR) are reported for continuous composite scores, and between-subgroup comparisons are done using Mann-Whitney $U$ tests. Spearman's correlation coefficients were determined between domains. Multiple regression was modelled to predict the behavioural composite score by entering the knowledge composite score, attitude composite score, and relevant participants' background variables.

Statistical analysis was performed with SPSS (Windows version 22.0; IBM Corp, Armonk [NY], United States).

\section{Results}

A total of 247 doctors in the nine EDs were eligible for inclusion, and questionnaire forms were distributed to all eligible physicians. In all, 140 questionnaires were returned (response rate: 57\%). Seventy-nine (56.4\%) of the respondents were Fellows, 94 (67.1\%) had $\geq 5$ years of experience in EM, 39 (27.9\%) had attended the ACLS within the most recent 2 years, 20 (14.3\%) were ACLS instructors, and 45 (32.1\%) had attended courses on TOR or breaking bad news.

A summary of the responses to the survey is shown in Table 2 . The questions are categorised into knowledge, attitudes, behaviours, and miscellaneous. The distribution of responses for each question is shown. The Cronbach's alpha value of attitude questions (Questions A2-A5) was 0.603 and that of behaviour questions (Questions B1-B10) was 0.886 . The composite KAB scores of various subgroups are shown in Table 3.

A comparison of the KAB composite scores in terms of fellowship status showed no difference between Fellows and non-Fellows in terms of knowledge composite score (median $=3$, $\mathrm{IQR}=2-4$ vs median=3, IQR=2-3.5; $\mathrm{P}=0.080$ ). There was also no difference between the two groups' attitude composite scores (median $=20, \mathrm{IQR}=16$ 22 vs median=20, IQR=17-22; $\mathrm{P}=0.956)$. However, there was a statistically significant difference in behavioural composite scores between the two groups (median=24, IQR=19-27 vs median=28, $\mathrm{IQR}=24-30.8 ; \mathrm{P}<0.001$ ), indicating less aggressive resuscitation attempted by Fellows despite similar levels of knowledge and attitudes.

Subgroup analysis showed no differences in knowledge and attitude composite scores in terms of years postgraduation, with 10 years as the cut-off $(\mathrm{P}=0.194$ and $\mathrm{P}=0.128$, respectively). However, a significant difference was found in behavioural composite scores between the two groups $(<10$ years vs $\geq 10$ years: median 28 vs $25, \mathrm{P}=0.008$ ), implying that more experienced physicians are less aggressive. Physicians with $\geq 5$ years of experience in EM, despite having no difference in knowledge and attitudes, also demonstrated less aggressive resuscitation practices, with a lower behavioural composite score (median 25 vs $28, \mathrm{P}=0.004)$.

Regarding attendance of resuscitative courses (including ACLS), respondents who had attended the course within the previous 2 years showed no significant differences in either attitude or behavioural composite scores $(\mathrm{P}=0.785$ and 0.377 , respectively) compared with respondents who had most recently attended a course more than 2 years ago. In addition, being an ACLS instructor was associated with lower behavioural composite scores (median 22.5 vs $26, \mathrm{P}=0.009$ ) but similar attitude scores (median 20 vs 20, $\mathrm{P}=0.489$ ). For respondents who attended courses on TOR or breaking bad news, there was no difference in KAB compared with respondents who did not attend any related courses 
TABLE 2. Summary of the survey responses $(n=140)$ *

\begin{tabular}{|c|c|c|c|c|c|c|}
\hline \multirow{2}{*}{$\begin{array}{l}\text { Questionnaire } \\
\text { question }\end{array}$} & \multirow{2}{*}{$\begin{array}{l}\text { Positive } \\
\text { response }\end{array}$} & \multicolumn{5}{|c|}{ 5-point Likert scale } \\
\hline & & $\begin{array}{l}\text { Strongly } \\
\text { agree }\end{array}$ & Agree & Neutral & Disagree & $\begin{array}{l}\text { Strongly } \\
\text { disagree }\end{array}$ \\
\hline \multicolumn{7}{|l|}{ Knowledge } \\
\hline $\mathrm{K} 1$ & 25 (17.9\%) & & & & & \\
\hline K2 & 107 (76.4\%) & & & & & \\
\hline K3 & $61(43.6 \%)$ & & & & & \\
\hline K4 & 60 (42.9\%) & & & & & \\
\hline K5 & 79 (56.4\%) & & & & & \\
\hline K6 & $53(37.9 \%)$ & & & & & \\
\hline K7 & $129(92.1 \%)$ & & & & & \\
\hline K8 & 133 (95.0\%) & & & & & \\
\hline \multicolumn{7}{|l|}{ Attitude } \\
\hline $\mathrm{A} 1$ & $104(74.3 \%)$ & & & & & \\
\hline $\mathrm{A} 2$ & & $10(7.1 \%)$ & $51(36.4 \%)$ & $49(35.0 \%)$ & $21(15.0 \%)$ & $9(6.4 \%)$ \\
\hline A3 & & $14(10.0 \%)$ & $68(48.6 \%)$ & 39 (27.9\%) & 15 (10.7\%) & $4(2.9 \%)$ \\
\hline A4 & & $7(5.0 \%)$ & 45 (32.1\%) & $34(24.3 \%)$ & $44(31.4 \%)$ & $10(7.1 \%)$ \\
\hline A5 & & $6(4.3 \%)$ & $54(38.6 \%)$ & $33(23.6 \%)$ & $41(29.3 \%)$ & $6(4.3 \%)$ \\
\hline \multirow[t]{3}{*}{ A6 } & & $4(2.9 \%)$ & $36(25.7 \%)$ & 25 (17.9\%) & 46 (32.9\%) & $29(20.7 \%)$ \\
\hline & & \multicolumn{5}{|c|}{ Scoring } \\
\hline & & 0 & 1 & 2 & 3 & 4 \\
\hline \multicolumn{7}{|l|}{ Behaviour } \\
\hline B1 & & $81(57.9 \%)$ & 47 (33.6\%) & $12(8.6 \%)$ & 0 & 0 \\
\hline B2 & & $24(17.1 \%)$ & 49 (35.0\%) & 49 (35.0\%) & $17(12.1 \%)$ & $1(0.7 \%)$ \\
\hline B3 & & 42 (30.0\%) & $28(20.0 \%)$ & $49(35.0 \%)$ & $21(15.0 \%)$ & 0 \\
\hline B4 & & 13 (9.3\%) & $16(11.4 \%)$ & $53(37.9 \%)$ & $41(29.3 \%)$ & $17(12.1 \%)$ \\
\hline B5 & & $4(2.9 \%)$ & $10(7.1 \%)$ & $39(27.9 \%)$ & 69 (49.3\%) & 18 (12.9\%) \\
\hline B6 & & $8(5.7 \%)$ & $11(7.9 \%)$ & $45(32.1 \%)$ & 59 (42.1\%) & $17(12.1 \%)$ \\
\hline B7 & & 0 & $6(4.3 \%)$ & 15 (10.7\%) & 49 (35.0\%) & $70(50.0 \%)$ \\
\hline B8 & & 0 & $4(2.9 \%)$ & 13 (9.3\%) & 28 (20.0\%) & 95 (67.9\%) \\
\hline B9 & & $2(1.4 \%)$ & $2(1.4 \%)$ & 14 (10.0\%) & 39 (27.9\%) & $83(59.3 \%)$ \\
\hline B10 & & 0 & $1(0.7 \%)$ & $7(5.0 \%)$ & $8(5.7 \%)$ & 124 (88.6\%) \\
\hline \multicolumn{7}{|l|}{ Others } \\
\hline 01 & & $8(5.7 \%)$ & $31(22.1 \%)$ & 39 (27.9\%) & 48 (34.3\%) & $14(10.0 \%)$ \\
\hline $\mathrm{O} 2$ & & 117 (83.6\%) & $16(11.4 \%)$ & $4(2.9 \%)$ & $2(1.4 \%)$ & $1(0.7 \%)$ \\
\hline O3 & & 26 (18.6\%) & 21 (15.0\%) & 26 (18.6\%) & 28 (20.0\%) & 39 (27.9\%) \\
\hline $\mathrm{O} 4$ & & $23(16.4 \%)$ & 46 (32.9\%) & 36 (25.7\%) & 28 (20.0\%) & 7 (5.0\%) \\
\hline O5 & & $1(0.7 \%)$ & 11 (7.9\%) & 38 (27.1\%) & 63 (45.0\%) & 27 (19.3\%) \\
\hline
\end{tabular}

* Data are presented as No. (\%)

$(\mathrm{P}=0.204,0.692$, and 0.315 , respectively).

Multiple regression to predict behavioural composite score demonstrated two independent predictors (Table 4). Status as a Fellow was found to be an independent predictor of lower behavioural composite score, that is, less aggressive resuscitation $(\beta=-0.314, P=0.028)$. Status as an ACLS instructor was also found to be an independent predictor to less aggressive resuscitation $(\beta=-0.217, \mathrm{P}=0.032)$.
Other variables, including ACLS attendance within 2 years, more than 10 years postgraduation, and years of experience in EM had no statistically significant association with any difference in behavioural composite scores.

As this survey aimed to study the relationship between KAB of TOR, Spearman's correlation coefficients were calculated to evaluate the correlations between these three domains. The 
TABLE 3. Knowledge, attitude, and behavioural composite scores on termination of resuscitation in various subgroups*

\begin{tabular}{|c|c|c|c|c|c|c|}
\hline \multirow[t]{2}{*}{ Questionnaire question } & \multicolumn{2}{|c|}{ Knowledge composite score } & \multicolumn{2}{|c|}{ Attitude composite score } & \multicolumn{2}{|c|}{ Behavioural composite score } \\
\hline & Score & $P$ value & Score & $P$ value & Score & $P$ value \\
\hline All $(n=140)$ & $3(2-4)$ & & $20(16-22)$ & & $25(22-30)$ & \\
\hline Fellowship status & & 0.080 & & 0.956 & & $<0.001$ \\
\hline Fellow $(n=79)$ & $3(2-4)$ & & $20(16-22)$ & & $24(19-27)$ & \\
\hline Non-Fellow (n=61) & $3(2-3.5)$ & & $20(17-22)$ & & $28(24-30.8)$ & \\
\hline Years since graduation from medical school & & 0.194 & & 0.128 & & 0.008 \\
\hline$<10$ years $(n=58)$ & $3(2-4)$ & & $20(17-22)$ & & $28(23-31)$ & \\
\hline$\geq 10$ years $(n=82)$ & $3(2-4)$ & & $18.5(16-22)$ & & $25(20.8-28)$ & \\
\hline Experience in EM & & 0.026 & & 0.307 & & 0.004 \\
\hline$<5$ years $(n=46)$ & $3(2-3)$ & & $20(17.5-22)$ & & $28(24-31)$ & \\
\hline$\geq 5$ years $(n=94)$ & $3(2-4)$ & & $19(16-22)$ & & $25(20.8-28)$ & \\
\hline Religious belief & & 0.292 & & 0.626 & & 0.956 \\
\hline Yes $(n=45)$ & $3(2-4)$ & & $19.5(15.3-22)$ & & $25(22-28.8)$ & \\
\hline No $(n=95)$ & $3(2-4)$ & & $20(17-22)$ & & $26(21-30)$ & \\
\hline Gender & & 0.003 & & 0.923 & & 0.143 \\
\hline Male $(n=105)$ & $3(2-4)$ & & 19 (16.3-22) & & $25(21-30)$ & \\
\hline Female $(n=35)$ & $3(2-3)$ & & $20(16-22)$ & & $27(23-30)$ & \\
\hline Attended ACLS course within 2 years & & $<0.001$ & & 0.785 & & 0.377 \\
\hline Yes $(n=39)$ & $2(1-3)$ & & $20(16-22)$ & & $26(22-31)$ & \\
\hline No $(n=101)$ & $3(2-4)$ & & $19(16.3-22)$ & & $25(22-28.8)$ & \\
\hline ACLS instructor & & 0.526 & & 0.489 & & 0.009 \\
\hline Yes $(n=20)$ & $3(2.5-4)$ & & $20(13.5-22.8)$ & & $22.5(16-25.8)$ & \\
\hline No $(n=120)$ & $3(2-4)$ & & $20(17-22)$ & & $26(22-30)$ & \\
\hline $\begin{array}{l}\text { Attended course on breaking bad news or } \\
\text { termination of resuscitation }\end{array}$ & & 0.204 & & 0.692 & & 0.315 \\
\hline Yes $(n=45)$ & $3(3-4)$ & & $19.5(17-22)$ & & $25(21-28.8)$ & \\
\hline No $(n=95)$ & $3(2-4)$ & & $20(16-22)$ & & $26(22-30)$ & \\
\hline
\end{tabular}

Abbreviations: ACLS = Advanced Cardiac Life Support; EM = emergency medicine

* Data are shown as median (interquartile range), unless otherwise specified

TABLE 4. Multiple regression predicting behavioural composite score

\begin{tabular}{lccccc}
\hline Predictors & $\begin{array}{c}\text { Unstandardised } \\
\text { coefficients (B) [95\% Cl] }\end{array}$ & $\begin{array}{c}\text { Standard error } \\
\text { of B }\end{array}$ & $\begin{array}{c}\text { Standardised } \\
\text { coefficient ( } \beta \text { ) }\end{array}$ & t statistic & P value \\
\hline Fellow & $-3.912(-7.393$ to -0.43$)$ & 1.76 & -0.314 & -2.223 & 0.028 \\
ACLS instructor & $-3.816(-7.297$ to -0.334$)$ & 1.76 & -0.217 & -2.168 & 0.032 \\
Attended ACLS within 2 years & $1.333(-1.462$ to 4.128$)$ & 1.413 & 0.097 & 0.944 & 0.347 \\
Graduated from medical school >10 years & $0.519(-2.832$ to 3.87) & 1.694 & 0.041 & 0.306 & 0.76 \\
EM experience (years) & $0.201(-3.805$ to 4.208) & 2.025 & 0.015 & 0.099 & 0.921 \\
Knowledge composite score & $0.289(-0.574$ to 1.151) & 0.436 & 0.057 & 0.662 & 0.509 \\
Attitude composite score & $-0.169(-0.437$ to 0.099) & 0.135 & -0.103 & -1.25 & 0.214 \\
\hline
\end{tabular}

Abbreviations: $\mathrm{ACLS}=$ Advanced Cardiac Life Support; $\mathrm{Cl}=$ confidence intervals; $\mathrm{EM}=$ emergency medicine

correlations between the three domains were all statistically insignificant: knowledge and attitudes $(r=0.02 ; \quad \mathrm{P}=0.795)$, knowledge and behaviours $(r=0.011 ; \mathrm{P}=0.893)$, attitudes and behaviours $(r=$ relatives/parents of children) should be allowed 
to witness the resuscitation process with a nurse accompanying them. In contrast, 117 (83.6\%) indicated that they had never allowed relatives to be present during resuscitation in the past 6 months. A Chi squared test with linear-by-linear association indicated a positive trend $\left(X^{2}=7.095, \mathrm{P}=0.008\right)$.

When participants were asked whether a rule for TOR should be implemented in EDs, 104 (74.3\%) gave a positive response. An open-ended question was asked about the concerns with departmental TOR guidelines (Question O6). Each written answer given was reviewed by the authors. The answers were summarised. The main reasons for not following TOR guidelines were relatives' concerns $(\mathrm{n}=25)$, followed by patient's premorbid status/ clinical history $(n=24)$, and legal concerns $(n=18)$. A small number of participants gave answers related to limitations in flexibility, scientific evidence of TOR rules, usability, etc.

\section{Discussion}

An important concept in decisions about TOR is futility of treatment. This is based on the principle of the patient's best interest. ${ }^{11}$ Medical futility is a subjective term encompassing a range of possibilities in terms of whether a patient will benefit from efforts designed to improve his or her life and survival to discharge from a healthcare facility. ${ }^{12}$ A treatment that does not benefit the patient, even if there is a physiological effect, can be considered futile. ${ }^{13} \mathrm{~A}$ mere return of spontaneous circulation would not benefit a patient if a meaningful existence cannot be achieved. On the contrary, this may even lead to extra burdens on the patients, such as unmanageable pain and suffering or a traumatic and undignified death. ${ }^{11}$ Prolonged resuscitation of OHCA patients may also burden the resources and manpower of EDs and society. ${ }^{14,15}$ Focusing resources on patients with very low chances of survival may defer resuscitative resources away from other patients who are critically ill. ${ }^{16}$ However, early TOR also has drawbacks including potential ethical arguments, legal concerns, and breakdown of communication with relatives of the deceased.

Different guidelines and clinical prediction rules on TOR have been developed and validated for prognostication and identification of medically futile patients. Examples include guidelines from the American Heart Association, the universal TOR guideline, the modified basic life support TOR rule, the modified advanced life support TOR rule, and the neurological TOR rule. ${ }^{2-6}$ Most of these guidelines were validated in the prehospital setting, but the information is also applicable in the ED setting. In Hong Kong, EM services do not apply any prehospital TOR rules except in a few circumstances such as injuries incompatible with life or obvious post-mortem changes. A 2013 study showed that the percentages of OHCA patients being resuscitated despite meeting the advanced life support TOR rule or the neurologic TOR rule were $39.8 \%$ and $26.9 \%$, respectively. ${ }^{17}$ In the group of OHCA patients in whom continuation of resuscitation was medically futile, care should be focused on communication with and psychological and bereavement support to the relatives instead of continuing medical treatment, which would not be beneficial to patients and relatives.

In this study, two independent variables impacting less aggressive resuscitation behaviour were identified: status as a Fellow or ACLS instructor. As we expected, Fellows were less aggressive in terms of resuscitation of medically futile OHCA patients. However, more years since graduation and more years of experience in EM, although expected to be associated with greater general medical knowledge about resuscitation, were not associated with less aggressiveness in resuscitation. One of the reasons for this may be the expectations of the general public, as Fellows are generally more recognised by the public. They may have more confidence in terminating resuscitation and explaining the decision to patients' relatives. Therefore, the concept of medical futility, TOR clinical prediction rules, communication, and bereavement skills should receive more emphasis in pre-Fellowship EM training. Opinions and support from Fellows may also be sought when handling OHCA patients.

Status as an ACLS instructor was also an independent predictor of less aggressive resuscitation attempts. Although their knowledge of TOR was not found to differ significantly from that of non-ACLS instructors, they should have more knowledge about the resuscitation process itself. They may potentially know more about the harm and futility of prolonged resuscitation. Meanwhile, there were no difference in either attitudes or behaviours regarding TOR between those who attended an ACLS more or less than 2 years ago. The ACLS focuses on medical knowledge about advanced life support instead of the prognostication and management of medically futile cases. For doctors who had attended courses related to TOR or breaking bad news, no difference was found in terms of KAB of TOR. One of the reasons for this may be the content of the course. Some of the courses on breaking bad news focus on communication skills. Those practices may have a presumptive clinical scenario, such as explaining the condition of a cardiopulmonary-arrested patient to his/her relatives with empathy. Rather, the decision of early TOR and the rationale behind it may not be adequately discussed. More discussion of medical futility and its ethical basis should be done before proceeding to the step of communication with relatives.

No correlations were found between 
physicians' level of knowledge about TOR, their attitudes towards TOR, and their aggressiveness with resuscitation. This was not surprising, as many participants expressed concerns about TOR, including patients' premorbid status, clinical histories, reactions from family members, and medicolegal concerns about early withdrawal and TOR. These factors, which affect the decision of TOR versus continuation of resuscitation, are likely independent from physicians' own knowledge and attitudes. This explains why having more knowledge or open-mindedness towards acceptance of TOR did not necessarily lead to less aggressiveness in resuscitation attempts.

Approximately $54 \%$ of participants disagreed with the presence of relatives in resuscitation, and $84 \%$ never allowed relatives to be present during the resuscitation process. This warrants discussion, as some opinions and studies overseas have suggested that family members who witnessed the patient's resuscitation process had better mental health outcomes irrespective of the patient's final survival outcome. ${ }^{18}$ Family members' grieving process may also be enhanced. ${ }^{18}$ However, there are practical considerations, including the limitation of availability of trained personnel to accompany the family members and limitations of space in the resuscitation room.

Of our participants, $74 \%$ agreed that there is a need to develop TOR rules in Hong Kong. When participants were asked their concerns about following TOR rules, many of them responded that potential medicolegal liability was one of the main problems. This is understandable, as the tendency towards defensive medical practices has progressed in recent years. However, prolongation of the resuscitative process for futile patients, apart from being nonempathetic, might not make a doctor less vulnerable to complaints. Instead, good communication with relatives and bereavement support is always the key to reduction of family members' misunderstanding and emotional reactions.

\section{Limitations}

This study had a few limitations. First, the response rate was $57 \%$, which is borderline satisfactory. This may result in volunteer response bias, as doctors who returned the questionnaires were likely to have more interest in and stronger opinions about TOR. This may cause an underestimation of the overall aggressiveness of resuscitation (falsely low behavioural composite scores). In addition, the study does not include sample size planning.

Another limitation of this study was the questionnaire contents. As discussed previously, no validated questionnaires concerning similar topics were discovered by a literature search. Further, no previous similar studies had been done in Hong
Kong. Therefore, the questions in this survey were designed based on multiple previous studies with similar topics. There was no external validation of the questionnaire tool.

The questions on attitudes about TOR assessed the participants' attitudes towards aggressiveness of resuscitation (as the opposite of TOR) and medically futile resuscitation. For questions concerning TORrelated behaviours, the calculation of composite scores was based on participants' self-reported behaviour rather than their actual practices. Therefore, reporting bias may exist. The reported answers may underestimate the participants' aggressiveness in resuscitation, as they knew that the theme of this study was TOR. Participants may have answered as if they were being less aggressive.

Another drawback of the behavioural questions is the arbitrary scale for the scoring. A more objective assessment would be to quantify the duration of resuscitation in terms of minutes or number of adrenaline injections. However, as the scenarios only contained simple patient information, it may be difficult for the participants to comment quantitatively on the duration of resuscitation. This may lead to further inaccuracy. Therefore, an arbitrary scale was used, with a reference range of 0 being no resuscitation and 4 being relatively prolonged resuscitation for a young, healthy adult.

To minimise this discrepancy, further observational studies on doctors' actual performance during TOR could be performed.

\section{Conclusion}

Clinical practice and behaviour of TOR were not demonstrated to have any association with knowledge or attitudes. Status as a Fellow or ACLS instructor were the only two parameters identified to have a significant relationship with earlier TOR in medically futile OHCA patients.

\section{Author contributions}

All authors had full access to the data, contributed to the study, approved the final version for publication, and take responsibility for its accuracy and integrity.

Concept and design of study: CW So, CT Lui, KL Tsui. Acquisition of data: CW So, KL Chan, AKK Law, YK Wong, T Li, CL Wong, SC Leung.

Analysis or interpretation of data: CW So, CT Lui, KL Tsui. Drafting of the manuscript: CW So, CT Lui, KL Tsui.

Critical revision for important intellectual content: All authors.

\section{Acknowledgement}

The authors thank the Emergency Care Research Consortium of the Hong Kong College of Emergency Medicine for assistance with liaison between the participating site investigators. We acknowledge the coordinators of all participating centres. 


\section{Conflicts of interest}

The authors have no conflicts of interest to disclose.

\section{Declaration}

This paper was presented to the Education Committee of the Hong Kong College of Emergency Medicine during the Scientific Symposium on Emergency Medicine (SSEM) on 26 October 2018 for examination purpose.

\section{Funding/support}

This research received no specific grant from any funding agency in the public, commercial, or not-for-profit sectors.

\section{Ethics approval}

The Research Ethics Office of New Territories West Cluster waived the need for ethical approval for this questionnaire survey. This study was conducted in accordance with the Declaration of Helsinki. The nature and purpose of the study was explained to participants, and those who returned completed questionnaires were assumed to have provided consent.

\section{References}

1. Fan KL, Leung LP, Siu YC. Out-of-hospital cardiac arrest in Hong Kong: a territory-wide study. Hong Kong Med J 2017;23:48-53.

2. Mancini ME, Diekema DS, Hoadley TA, et al. Part 3: Ethical issue: 2015 American Heart Association guidelines update for cardiopulmonary resuscitation and emergency cardiovascular care. Circulation 2015;132(18 Suppl 2):S383-96.

3. Kim TH, Shin SD, Kim YJ, Kim CH, Kim JE. The scene time interval and basic life support termination of resuscitation rule in adult out-of-hospital cardiac arrest. J Korean Med Sci 2015;30:104-9.

4. Ruygrok ML, Byyny RL, Haukoos JS; Colorado Cardiac Arrest \& Resuscitation Collaborative Study Group and the Denver Metro EMS Medical Directors. Validation of 3 termination of resuscitation criteria for good neurological survival after out-of-hospital cardiac arrest. Ann Emerg Med 2009;54:239-47.

5. Chiang WC, Ko PC, Chang AM, et al. Predictive performance of universal termination of resuscitation rules in an Asian community: are they accurate enough? Emerg Med J 2015;32:318-23.

6. Cheong RW, Li H, Doctor NE, et al. Termination of resuscitation rules to predict neurological outcomes in outof-hospital cardiac arrest for an intermediate life support prehospital system. Prehosp Emerg Care 2016;20:623-9.

7. Bae H, Lee S, Jang HY. The ethical attitude of emergency physicians towards resuscitation in Korea. J Emerg Med 2008;34:485-90.

8. Elo G, Diószeghy C, Dobos M, Andorka M. Ethical considerations behind the limitation of cardiopulmonary resuscitation in Hungary-the role of education and training. Resuscitation 2005;64:71-7.

9. Baird G, Sammy I, Nunes P, Paul J. Attitudes and practices regarding resuscitation in emergency departments in Trinidad and Tobago. Emerg Med J 2014;31:889-93.

10. Einav S, Alon G, Kaufman N, et al. To resuscitate or not to resuscitate: a logistic regression analysis of physicianrelated variables influencing the decision. Emerg Med J 2012;29:709-14.

11. Hospital Authority, Hong Kong SAR Government. HA guideline on Do-Not-Attempt cardiopulmonary resuscitation (DNACPR). 2016. Available from: http:// www.ha.org.hk/haho/ho/psrm/CEC-GE-6_en.pdf. Accessed 26 Aug 2018.

12. The Free Dictionary by Farlex. Medical futility. Available from: https://medical-dictionary.thefreedictionary.com/ medical+futility. Accessed 27 Aug 2017.

13. Jecker NS. Medical futility. School of Medicine, University of Washington. Available from: https://depts.washington. edu/bioethx/topics/futil.html. Accessed 26 Aug 2018.

14. Millin MG, Khandker SR, Malki A. Termination of resuscitation of nontraumatic cardiopulmonary arrest: resource document for the National Association of EMS Physicians position statement. Prehosp Emerg Care 2011;15:547-54.

15. Valenzuela TD, Criss EA, Spaite D, Meislin HW, Wright AL, Clark L. Cost-effectiveness analysis of paramedic emergency medical services in the treatment of prehospital cardiopulmonary arrest. Ann Emerg Med 1990;19:1407-11.

16. Millin MG, Galvagno SM. More than 15 minutes of resuscitation prior to termination of resuscitation results in undue harm to the public health. Am J Emerg Med 2016;34:1689-90.

17. Chan KM, Lui CT, Tsui KL, Tang YH. Comparison of clinical prediction rules for termination of resuscitation of out-of-hospital cardiac arrests on arrival to emergency department. Hong Kong J Emerg Med 2013;20:343-51.

18. DeWitt S. Should family-witnessed resuscitation become our standard? J Emerg Med 2015;49:500-2. 